ARTICLE

Received 29 Jul 2013 | Accepted 16 May 2014 | Published 12 Jun $2014 \quad$ DOI: 10.1038/ncomms5143

\title{
Silicate deposition during decomposition of cyanobacteria may promote export of picophytoplankton to the deep ocean
}

Tiantian Tang ${ }^{1, \dagger}$, Kim Kisslinger $^{2} \&$ Cindy Lee ${ }^{1}$

Marine particles transport organic matter through the water column to the sediment where the organic matter can be buried. This pathway is one of the few natural removal mechanisms of $\mathrm{CO}_{2}$ from the atmosphere over geological time. Picophytoplankton, major primary producers in the ocean, have until recently been thought unimportant regarding particle transport. Here we provide evidence that silicate is deposited on extracellular polymeric substance (EPS) associated with decomposing picophytoplankton. We also find that $\mathrm{Si}$ is enriched in a previously unexplored group of marine particles (called micro-blebs) from the deep-water column. The surprising similarity in morphology and composition between EPS-Si and micro-blebs suggests that EPS-Si may be a precursor of micro-blebs observed in the deep ocean. This previously unexplored source of silicon may be important to silicon cycling and may further enhance export of picophytoplankton to the deep ocean.

\footnotetext{
${ }^{1}$ School of Marine and Atmospheric Sciences, Stony Brook University, Stony Brook, New York 11794, USA. ${ }^{2}$ Center for Functional Nanomaterials, Brookhaven National Laboratory, Upton, New York 11973, USA. †Present address: Department of Earth and Planetary Science, Harvard University, 20 Oxford Street, Cambridge, Massachusetts 02138, USA. Correspondence and requests for materials should be addressed to T.T. (email: tiantiantang@fas.harvard.edu).
} 
P hotosynthetic picophytoplankton (organisms $0.2-2 \mu \mathrm{m}$ in size) are major primary producers that contribute more than $50 \%$ of the autotrophic biomass in oligotrophic ocean areas ${ }^{1,2}$. However, as a result of their small size, these picoplankton have long been considered to be less important to the transport of carbon from the atmosphere into the ocean that results from particle export ${ }^{3}$. Because of the widely observed quantitative relationship between particulate organic carbon (POC) and ballast minerals (for example, opal, carbonates and dust), biominerals from plankton like diatoms and coccolithophores are thought to contribute more, owing to density-driven particle sedimentation ${ }^{4,5}$. However, recent studies in oligotrophic areas have suggested that picophytoplankton are also important in transporting organic matter to the deep ocean ${ }^{6-8}$. The export mechanism is not clear, but it has been suggested that aggregation of picophytoplankton, and fecal pellets from grazers, can facilitate the settling of this material into the deep ocean ${ }^{6,8}$.

To better understand mechanisms of cyanobacterial export in the marine environment, we conducted incubations of decomposing Synechococcus cells, during which we discovered that silicon can deposit on the detrital organic matter. This finding suggests a novel mechanism to explain our discovery of a new group of marine particles enriched in Si (micro-blebs) collected from a Bermuda Rise site in the North Atlantic Ocean.

\section{Results}

Degradation incubation of cyanobacteria. In the incubations, we used two strains of the cyanobacterium, Synechococcus sp. (CCMP2370 and CCMP1334). These are open-ocean strains that were originally isolated from the Sargasso Sea where cyanobacteria are major primary producers for most of the year ${ }^{2}$. Cyanobacterial cells harvested during the late exponential phase were added to coastal seawater (Stony Brook Harbor, NY, USA) and allowed to decompose in the dark in the presence of natural microbial communities. Before adding cyanobacteria to the coastal seawater, mesozooplankton and larger zooplankton were removed by filtration so that microbial degradation dominated the incubations. Controls were also run where no cyanobacteria were added, and where the medium was sterilized before adding cyanobacteria. The seawater used in the incubations initially contained $1.8 \pm 1.4 \mu \mathrm{moll}^{-1}$ biogenic silicate (BSi) and $30 \pm 1.5 \mu \mathrm{moll}^{-1}$ dissolved silicic acid $\left(\mathrm{H}_{4} \mathrm{SiO}_{4}\right)$ (Fig. 1 and Supplementary Fig. 1). Subsamples were collected over time to track microbial degradation of Synechococcus cells.

The subsamples collected over time during the incubations were observed using transmission electron microscopy (TEM) and scanning electron microscopy (SEM) with the purpose of investigating the change in morphology and elemental composition of detrital organic matter during cell degradation. The spherical or ellipsoidal shapes of Synechococcus dominated the initial samples (Fig. 2a,b). Other phytoplankton species were much less frequently observed compared with the added Synechococcus cells, and were considered unimportant in this experimental setting. Also present were extracellular fibrillar structures, which are similar in morphology to extracellular polymeric substances (EPS) commonly found in marine environments ${ }^{9,10}$. Similar structures of EPS have also been widely observed in cyanobacterial cultures ${ }^{11}$. Some EPS were present in initial cell cultures, but they were more abundant than intact cells in degraded samples. After 2 days of incubation in experiments with bacteria present, most cells had lysed and lost their shapes (Fig. 2c,d). Lysed cells were surrounded by an abundance of EPS, although much of this EPS was not visibly attached to cells. Newly produced EPS would most likely originate from cyanobacteria or a
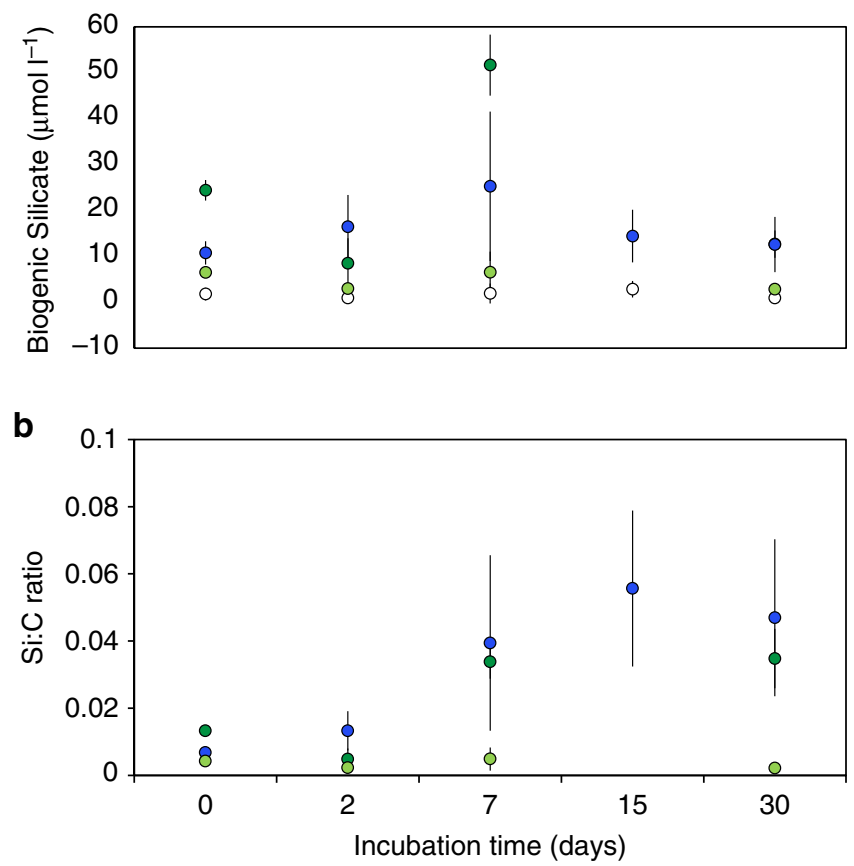

Figure 1 | BSi concentration and BSi/POC ratios. Changes in $\mathrm{BSi}$ concentration (a) and ratio of BSi to particulate organic carbon (b) during incubation of Synechococcus CCMP2370 (dark green circles) and CCMP1334 (blue circles) in coastal seawater. CCMP2370 cells were incubated in autoclaved seawater (light green circles) in parallel to show any changes occurring in the absence of microbes. Coastal seawater (open circles) without addition of Synechococcus cells was also incubated in parallel to show any changes occurring in natural seawater. The error bars represent standard deviation.

heterotrophic bacteria ${ }^{12,13}$, since other organisms were a minor component. TEM pictures of both intact (Fig. 2c,e) and thinsectioned samples (Fig. 2d,f) showed that many of the EPS fibrils were progressively rearranged to form dark, sharp and elongated clusters during the incubation from day 2 to day 15 .

In addition, TEM selected area electron diffraction patterns showed that polycrystalline structures of several hundred nanometers in length formed after 2 days of degradation. These structures were commonly observed in both day 2 and day 15 incubation samples (Fig. 2c,e), but were rare in samples incubated in the sterilized medium. The polycrystalline structures were morphologically similar to the silicate mineral smectite that has been found to associate with organic matter in California continental margin sediments ${ }^{14}$. It has been suggested that smectite can be produced authigenically at low temperatures in association with bacteria ${ }^{15}$. Energy dispersive X-ray spectroscopy (EDS) mounted on SEM demonstrated that these atomicallydense structures were enriched in $\mathrm{Si}$ and $\mathrm{Mg}$ compared with adjacent intact Synechococcus cells (Fig. 3). We did not detect any accumulation of these crystals inside cyanobacterial cells.

Chemical analysis provides further support for the idea that $\mathrm{Si}$ becomes associated with EPS during the degradation of cyanobacteria cells. Biogenic silicate concentration, [BSi], increased to as much as $52 \pm 7 \mu \mathrm{moll}^{-1}$ after 7 days of degradation of the two strains (Fig. 1), compared with the much lower [BSi] in cultures incubated in the sterilized medium (average $6.5 \pm 4.5 \mu \mathrm{moll}^{-1}$ ) and in seawater without cyanobacteria added (average $2.8 \pm 1.8 \mu \mathrm{moll}^{-1}$ ). BSi that formed during degradation decreased in concentration after 7 days, with only $13 \pm 3 \mu \mathrm{mol}^{-1}$ remaining on day 30 of the incubation. The ratio 

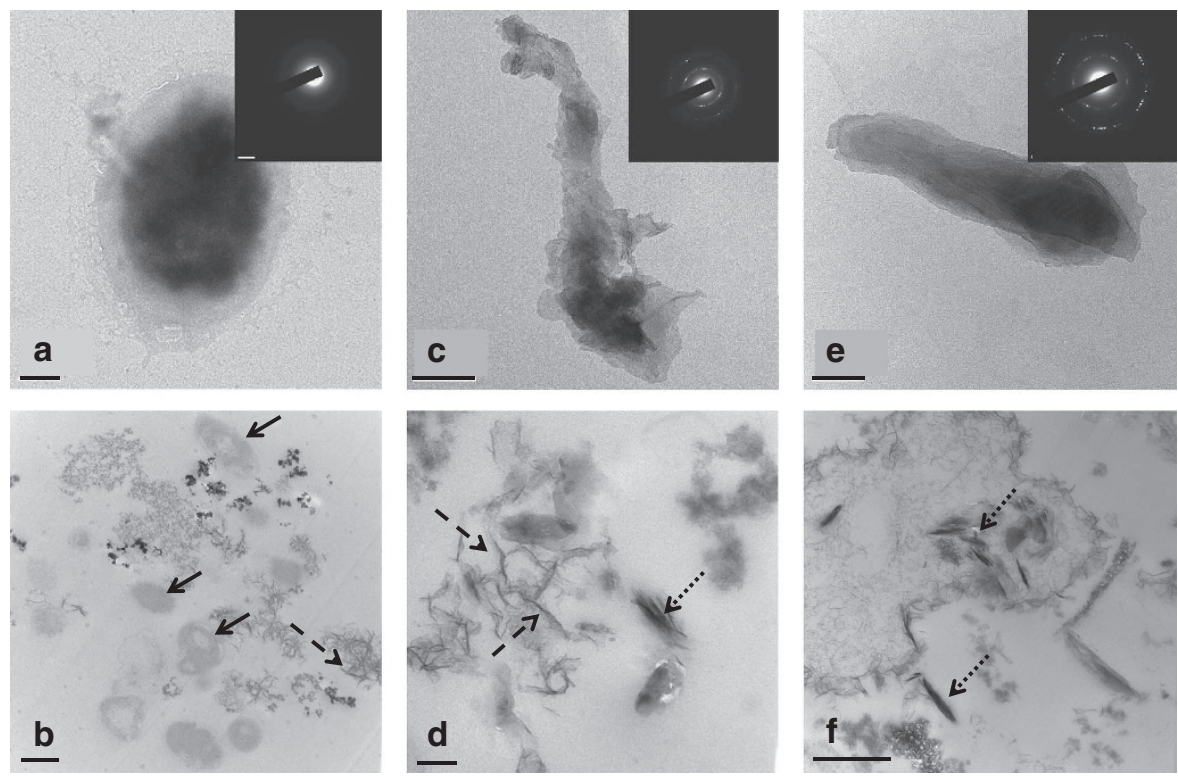

Figure 2 | TEM images of decomposing Synechococcus cells. Samples were taken during the dark incubation of Synechococcus cells in coastal seawater with natural microbial communities, initially $\left(\mathrm{t}_{0},(\mathbf{a}, \mathbf{b})\right)$, after 2 days $\left(\mathrm{t}_{2},(\mathrm{c})\right.$ and $(\mathrm{d})$ ) and after 15 days $\left(\mathrm{t}_{15}\right.$, (e, $\left.\mathbf{f}\right)$ ). Selected area electron diffraction patterns are pictured in $\mathbf{a}, \mathbf{c}$, and $\mathbf{e}$, and reflect the crystallographic axis orientation changing across grain boundaries; polycrystalline structures were characterized by rings of luminous points in $\mathbf{c}$ and $\mathbf{e} . \mathbf{b}, \mathbf{d}$ and $\mathbf{f}$ are images of 80-nm thick thin sections of samples after chemical fixation. Synechococcus cells were marked by solid arrows in $\mathbf{b}$. Fibrillar-like EPS were marked by dash arrows in $\mathbf{b}$ and $\mathbf{d}$. Electronically dense fibrillar-like particles were marked by dot arrows in $\mathbf{d}$ and $\mathbf{f}$ (Scale bars, $200 \mathrm{~nm}$ in $\mathbf{a}, 500 \mathrm{~nm}$ in $\mathbf{b}, 100 \mathrm{~nm}$ in c, $100 \mathrm{~nm}$ in $\mathbf{d}, 100 \mathrm{~nm}$ in $\mathbf{e}$ and $500 \mathrm{~nm}$ in f).

a

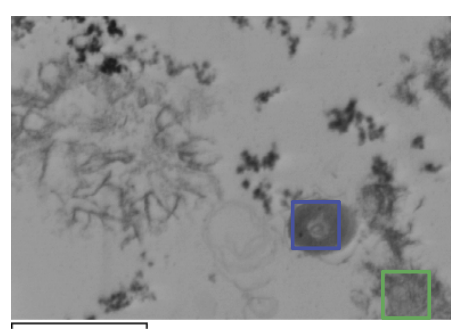

b

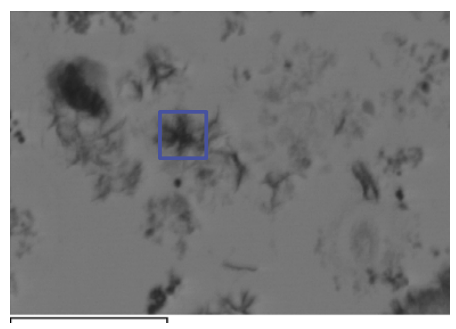

C

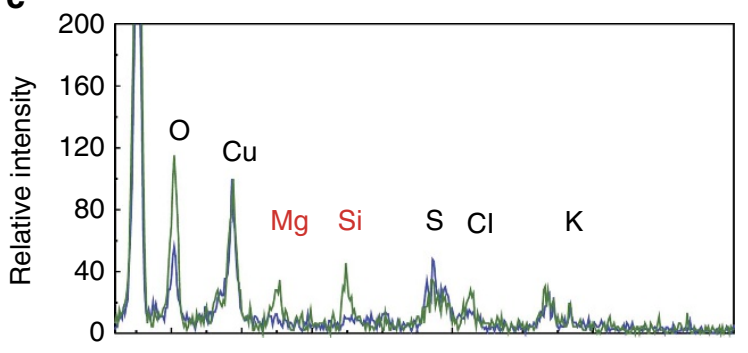

d

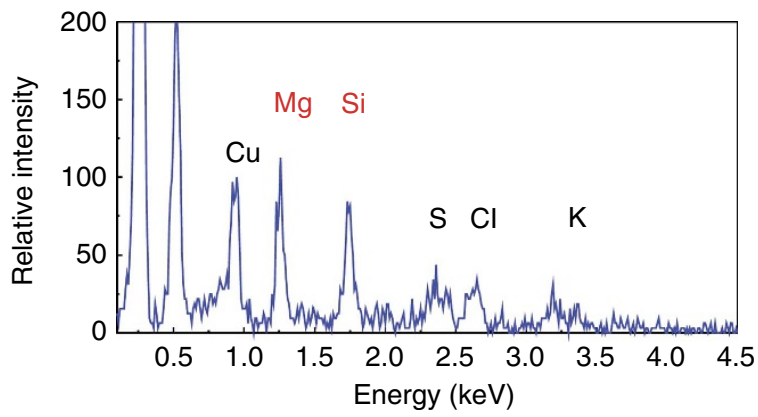

Figure 3 | Scanning transmission electron microscope images and EDS spectra of decomposing Synechococcus cells. Images were taken on thinsectioned samples $(80 \mathrm{~nm})$ collected during dark incubation of Synechococcus cells after 2 days (a) and 15 days (b). After 2 days, the EDS spectrum (blue spectrum in c) of an intact cyanobacterial cell (blue box in $\mathbf{a}$ ) shows the absence of $\mathrm{Mg}$ and Si inside the cell. However, the EPS adjacent to the cell (green box in a) accumulated both $\mathrm{Mg}$ and $\mathrm{Si}$ (Green spectrum in c), as did the EPS in the more degraded samples (blue box in $\mathbf{b}$ and blue spectrum in $\mathbf{d}$ ). The observed Cu was from the copper grid holder (Scale bar, $1 \mu \mathrm{m}$ ).

Si:C (BSi to particulate organic carbon) was elevated (as high as 0.056 ) in cultures with degrading cyanobacteria, in contrast to the constant and lower Si:C (0.003) in cells incubated in sterile medium (Fig. 1). Meanwhile, the relative abundance of glycine in dissolved hydrolysable amino acids was significantly enriched at the end of incubation, which supports evidence that Si-associated amino acids are enriched in glycine ${ }^{16}$ (Supplementary Fig. 2). All these results observed in experiments with microbes present compared with the sterile control show the importance of the degradation process to $\mathrm{Si}$ deposition, whatever the mechanism. The subsequent decrease in BSi after 2 weeks is probably owing to both dissolution of BSi and loss of organic matter, whether from 
a

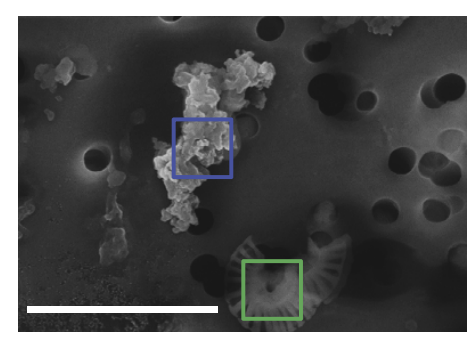

b

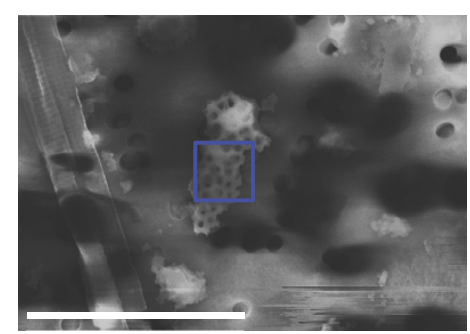

C

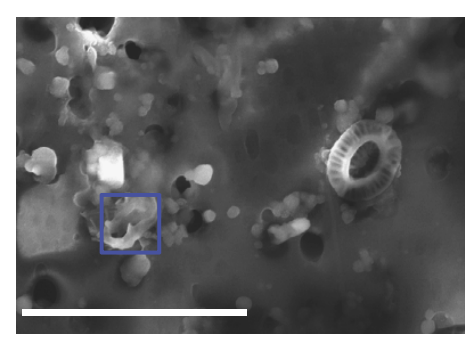

d

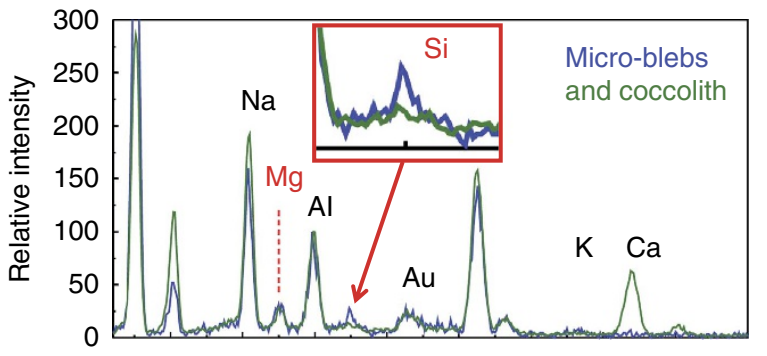

e

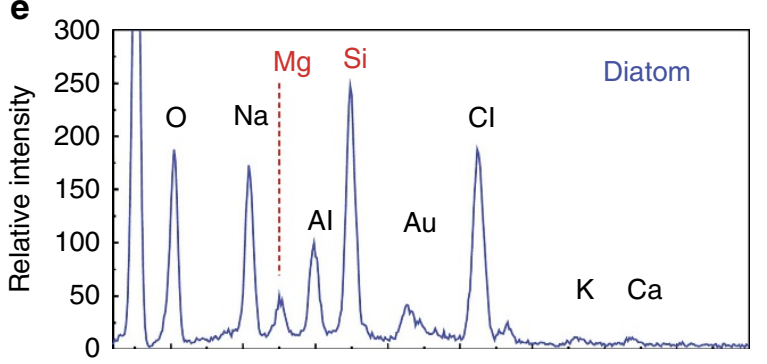

$\mathbf{f}$

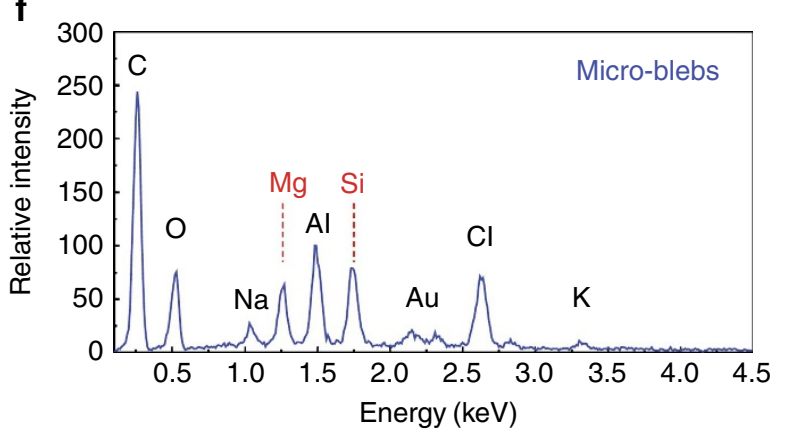

Figure 4 | SEM images of particles from Bermuda Rise. SEM images (a-c) and EDS spectra (d-f) of marine suspended particles collected from 2,000-m water depth (a,b,d and e) and from $50 \mathrm{~m}$ (c,f) near the Bermuda Rise. A micro-bleb (blue box in a and blue spectrum in d) and a coccolith fragment (green box in $\mathbf{a}$ and green spectrum in $\mathbf{d}$ ) are shown in $\mathbf{a}$ and $\mathbf{d}$, and a fragment of diatom frustule is shown as blue box in $\mathbf{b}$ and blue spectrum in e. A higher loading of particles is observed in surface water (c). The elemental compositions of micro-blebs were scanned by EDS. Micro-blebs from both surface (blue spectrum in $\mathbf{f}$ ) and 2,000 $\mathrm{m}$ (blue spectrum in $\mathbf{d}$ ) were enriched in both $\mathrm{Mg}$ and $\mathrm{Si}$. Enrichment of $\mathrm{Al}$ is from the aluminium holder (Scale bars, $5 \mu \mathrm{m}$ in $\mathbf{a}, 9 \mu \mathrm{m}$ in $\mathbf{b}$ and $7 \mu \mathrm{m}$ in $\mathbf{c}$ ).

cyanobacteria or from EPS ${ }^{17}$. The Si:C of $\sim 0.03$ to 0.06 in our Synechococcus degradation experiments are lower than ratios found in diatoms $(\sim 0.13)^{18}$. But given the higher abundance of picophytoplankton biomass in the open ocean ${ }^{2}$, cyanobacterial degradation and subsequent formation of Si-organic matter (Si$\mathrm{OM}$ ) association (that might serve as an important source of ballast) could account for up to $50 \%$ of the BSi inventory in the surface water (Supplementary Table 1).

We considered possible mechanisms for $\mathrm{Si}$ deposition in our experiments. First, cyanobacteria-derived EPS-associated Si and $\mathrm{Mg}$ do not result from silicate scavenging by brucite, $\left[\mathrm{Mg}(\mathrm{OH})_{2}\right]$, a mineral that forms in seawater when $\mathrm{pH}$ increases as a result of photosynthesis ${ }^{19}$. No brucite crystals were observed in cyanobacteria cultures $(\mathrm{pH}=8.9)$ incubated in coastal seawater, nor in cultures incubated in sterile seawater. Although $\mathrm{CO}_{2}$ is formed when cyanobacteria degrade over time, the $\mathrm{pH}$ during our incubations ranged between 7.5 and 8.1 , which is not favorable for brucite formation $(\mathrm{pH}>10)^{19}$. Second, EPS-associated Si does not originate from silicic acid dissolved from diatoms present in the coastal seawater used in the incubations, because very few diatoms were present, and silicic acid concentrations in all incubations, from 30 to $99 \mu_{\mathrm{moll}}^{-1}$ (Supplementary Fig. 1), were much lower than opal solubility of $1,600 \mu \mathrm{moll}^{-1}$ (ref. 20 ), but similar to silicic acid levels in most coastal environments as well as deep water of the North Atlantic Ocean (Supplementary Fig. 3). A third more likely explanation for the presence of EPS-associated $\mathrm{Si}$ and $\mathrm{Mg}$ is that EPS incorporates the Si from the Synechococcus cells ${ }^{21}$. Recent studies of both field and culture samples demonstrate that living cyanobacteria cells can accumulate significant amounts of $\mathrm{Si}^{22}$. As these cells begin to degrade, cell lysis could cause a local elevation of silicic acid concentration near the cells. Cell lysis can also produce large amounts of EPS, which could provide an organic template that selectively incorporates the elevated $\mathrm{Si}$. The progressive accumulation of $\mathrm{Mg}$ and $\mathrm{Si}$ in EPS may be related to the formation of the nano- to micro-crystalline particles we observed during degradation of the Synechococcus. In previous studies, fine grained silicate was also observed in fresh water biofilm and bacterial cultures ${ }^{15}$.

Marine particles from Bermuda rise. $\mathrm{Mg}-\mathrm{Si}$ deposition was not limited to laboratory samples. To study the existence of EPS-Si in natural particles, samples were collected at a site northeast of Bermuda in October 2011, as part of the BARFlux project. This site on the Bermuda rise has limited terrestrial input. Suspended particles of $0.8-5 \mu \mathrm{m}$ in size collected from a variety of depths were made up of three major types of particles, organic matterrich particles here called 'micro-blebs' (Fig. 4a, Supplementary 
Fig. 4) $\left(c . f_{.}{ }^{14}\right)$, carbonaceous coccolith-like fragments (Fig. 4a) and siliceous diatom-like frustules (Fig. 4b). The coccolith and diatom frustules had distinguishable geometrical structures, while micro-blebs had no well-defined or regularly arranged structures, but appeared to be loosely aggregated organic materials. These micro-blebs were also different from diatom frustules and coccoliths in their elemental compositions. EDS analysis suggested that micro-blebs were characterized by elevated $\mathrm{Si}$ and $\mathrm{Mg}$, which is similar to the EPS-associated Si observed in degrading cyanobacteria (Fig. 4, Supplementary Table 2). Diatom frustules were specifically enriched in $\mathrm{Si}$ but not $\mathrm{Mg}$, and coccoliths had a high abundance of $\mathrm{Ca}$ and $\mathrm{Mg}$ but not Si. Besides being enriched in $\mathrm{Si}$ and $\mathrm{Mg}$, neither micro-blebs nor the EPS-Si surrounding degrading cyanobacteria had regularly arranged biogenic geometrical structures. BSi analysis on parallel filters suggests that particles in the size range $0.8-5 \mu \mathrm{m}$ accounted for the majority of BSi (Supplementary Fig. 3). These visual, chemical and physical similarities lead us to speculate that EPS-Si produced during the degradation of marine cyanobacteria is one of the possible origins of the micro-blebs observed in marine particles. The $\mathrm{Al}$ seen in the spectra of marine particles was likely from the aluminium sample holder used in SEM as Al was absent in samples where the aluminium holder was not used (Supplementary Fig. 5). Therefore, dust particles, which are usually enriched in $\mathrm{Al}$ and $\mathrm{Si}$, probably have a limited contribution to these micro-blebs. Fecal pellets were found only in particles larger than $5 \mu \mathrm{m}$, so may not be a major source of these elements, but potentially function in packaging small particles in surface water and releasing these particles in mesopelagic water during decomposition ${ }^{23}$.

Contribution of cyanobacterial BSi to $\mathrm{Si}$ and $\mathrm{C}$ cycling. The potential contribution of Synechococcus-derived BSi to silicon and carbon flux was calculated for the Bermuda Rise site using estimates of various parameters from North Atlantic Ocean data (Supplementary Table 1 and references therein). The percentage of Si-associated OM in BSi was calculated from the EDS spectra as the ratio of $\mathrm{Si}$ concentrations in the $\mathrm{Si}-\mathrm{OM}$ particles (six particles, as in Supplementary Table 2) to the total Si concentrations in all the particles collected at 2,000-m depth (21 particles, as in Supplementary Table 2), or $11 \%$. Si concentrations mentioned here are the normalized Si concentrations that were relative to $\mathrm{Al}$, because $\mathrm{Al}$ is an artifact of the $\mathrm{Al}$ sample holder. This eliminates the effect from scanning time of each SEM spectra. Thus we assumed that $11 \%$ of exported BSi is in the form of $\mathrm{Si}-\mathrm{OM}$, of which the Si:C ratio of 0.042 (average $\mathrm{Si}: \mathrm{C}$ ratios from the later stage of incubations) was assumed for these $\mathrm{Si}-\mathrm{OM}$ particles. This results in a Si-OM-derived POC flux of $0.011 \mathrm{~g}$ $\mathrm{C} \mathrm{m}^{-2}$ per day, which is around $43 \%$ of the POC flux leaving the euphotic zone $\left(0.03 \mathrm{~g} \mathrm{C} \mathrm{m}^{-2} \text { per day }\right)^{2}$.

Synechococcus Si export can also be estimated from Synechococcus carbon export and the Si:C ratio, where Synechococcus carbon export was estimated from POC export, $0.026 \mathrm{~g} \mathrm{C} \mathrm{m}^{-2}$ per day, and the contribution of Synechococcus to POC flux, $2-13 \%$ (Supplementary Table 1 and references therein). This results in a Synechococcus Si export of $2-12 \mu \mathrm{mol} \mathrm{Si} \mathrm{m} \mathrm{m}^{-2}$ per day out of the euphotic zone, and accounts for $0.5-3 \%$ of the total annual Si export. This estimate of the contribution of Synechococcus to Si export is in the range of our calculation above that $11 \%$ of the $\mathrm{Si}$ in the deep ocean is in the form of Si-OM. This supports our suggestion that $\mathrm{Si}-\mathrm{OM}$ in the deep ocean on the Bermuda rise may originate from Synechococcus-derived Si.

In the surface water near Bermuda, Synechococcus-derived BSi (Syn-BSi) standing stock was estimated by multiplying Synechococcus biomass by the Syn-BSi production coefficient ${ }^{24}$. This production coefficient was calculated by dividing the average BSi produced by the fresh cell biomass added to the incubation, which indicates the BSi production of Synechococcus under ideal conditions. Syn-BSi standing stock accounts for $50 \%$ of the BSi inventory in the surface water, thus implying that half of the BSi in the surface water may originate from Synechococcus.

The following uncertainties should be considered with regard to the Syn-BSi budget in the open ocean: (1) The relative abundance of Si-OM in total BSi was calculated from EDS data, which scans only the surface of particles; thus the concentration reflects the elemental composition at the particle surface instead of the entire particle. It is possible that this method overestimates $\mathrm{Si}$ concentrations in the $\mathrm{Si}-\mathrm{OM}$ particles since $\mathrm{Si}$ and $\mathrm{Mg}$ may preferentially deposit on the surface of organic matter. (2) The Si:C ratio used in the calculations was from a 30-day Synechococcus incubation where cells were degraded solely by heterotrophic bacteria. It is not clear how $\mathrm{Si}$ :C would change over a much longer time scale, and also how other processes like zooplankton grazing change the Si:C ratio. Further work should be conducted to better evaluate these uncertainties.

\section{Discussion}

Cyanobacterial silicification has been observed previously in microfossils and in modern extreme environments like hot springs and sediments where amorphous silicate is supersaturated and $\mathrm{pH}$ is often extreme $\mathrm{e}^{25-28}$. However, the EPS-silicate found in this study is different, as it is deposited in the open ocean with its mild $\mathrm{pH}$ and opal undersaturation. Previous studies demonstrate that more than half of the biogenic silicate in the open ocean is detrital, and is not derived from siliceous phytoplankton like diatom as was previously thought ${ }^{29}$. Our finding of $\mathrm{Mg}-\mathrm{Si}$ deposits originating during decomposition of cyanobacteria implies a new source of detrital silicate to the oceans in addition to siliceous phytoplankton.

The close association between Si and EPS could also provide protection from remineralization for the EPS, while the increased Si content could contribute to density-driven particle export ${ }^{4}$ The EPS structure might also slow chemical dissolution of silica in the euphotic zone as suggested by the relatively constant $\mathrm{Si}: \mathrm{C}$ ratio at the end of the Synechococcus incubation. If we assume that the $\mathrm{Si}: \mathrm{C}$ ratio observed in the incubation is applicable in the deep ocean, Si-enriched organic matter could account for as much as $43 \%$ of the export production at Bermuda. Therefore, it must be considered in studies of particle flux in the open ocean. This finding provides an additional explanation for recent findings that pico- and nano-phytoplankton can be exported into the deep ocean ${ }^{6-8}$. Further investigation is needed to elucidate the contribution of this new type of biogenic silicate to the particle flux in marine environments.

\section{Methods}

Culture preparation. Strains of the cyanobacteria Synechococcus sp. CCMP2370 and CCMP1334 (Bigelow Laboratory) were grown in sterile L1 medium prepared with $0.2-\mu \mathrm{m}$ filtered coastal seawater (Stony Brook Harbor). The cultures were incubated at $20^{\circ} \mathrm{C}$ with a $16: 8$ illumination cycle of $\sim 1 \times 10^{4} \mu \mathrm{mol}_{\text {quanta }}{ }^{-2}$ $\mathrm{sec}^{-1}$. Cells were harvested at the end of the exponential growth stage or early stationary stage by centrifugation at $5,250 \mathrm{~g}$ for $40 \mathrm{~min}$. Pellets of cells were rinsed with and resuspended in $0.2 \mu \mathrm{m}$ filtered coastal seawater. Chlorophyll $a$ concentrations in collected cultures were estimated from the whole cell spectra from $600 \mathrm{~nm}$ to $800 \mathrm{~nm}$ using a Perkin Elmer UV-VIS spectrophotometer ${ }^{30}$. We measured chlorophyll $a$ as a way of ensuring that we were adding the same amount of cells to each incubation.

Incubation of cyanobacterial cells. Harvested cyanobacterial cells were added to coastal seawater (Stony Brook Harbor) that was filtered through $178-\mu \mathrm{m}$ mesh to remove large zooplankton. Cultures were adjusted to have the same chlorophyll concentrations. The incubations were conducted in sterilized polycarbonate flasks in the dark at $22-24^{\circ} \mathrm{C}$. Subsamples were collected after $0,2,7,15$ and 30 days. 
After centrifugation at $5,250 \mathrm{~g}$ for $40 \mathrm{~min}$, both the supernatants and pellets were collected as surrounding water and particle samples, respectively. No increase of plankton larger than $1 \mu \mathrm{m}$ was observed in 30-day incubations. Incubations of coastal seawater without Synechococcus present were also carried out under identical conditions as a blank control. A parallel incubation of Synechococcus CCMP2370 added to autoclaved coastal seawater was used as a sterile control. $\mathrm{pH}$ was measured in each subsample using a Ross electrode.

Marine suspended particle collection. Marine suspended particles were collected from a site northeast of Bermuda $\left(33.68^{\circ} \mathrm{N}, 57.6^{\circ} \mathrm{W}\right)$ on the R/V Endeavour in October 2011 (BaRFlux I). About 81 of seawater was collected from various depths using Niskin bottles on a rosette and transferred to a 10-1 acid rinsed container, which was then filtered through in-line polycarbonate filter holders with $5 \mu \mathrm{m}$ and $0.8 \mu \mathrm{m}$ polycarbonate filters in sequence. The filtrate was further filtered through $0.2-\mu \mathrm{m}$ polycarbonate filters using a Nalgene polysulfone filtration system. Glassware was avoided during sampling and storage. All filters were frozen until analysis of BSi and electron microscopy.

Bulk chemical analysis. BSi was collected during Synechococcus incubations on $0.2-\mu \mathrm{m}$ polycarbonate filters. The incubation samples as well as Bermuda samples were extracted with $0.2 \mathrm{M} \mathrm{NaOH}$ and measured colorimetrically as $\left[\mathrm{H}_{4} \mathrm{SiO}_{4}\right]$ in the extract ${ }^{31}$. Silicic acid $\left(\mathrm{H}_{4} \mathrm{SiO}_{4}\right)$ concentrations in $0.2 \mu \mathrm{m}$ filtered seawater samples were analyzed using the molybdate blue spectrophotometric method $^{32}$ on a Lachat flow injection colorimeter. POC samples from both Synechococcus incubations and Bermuda Rise seawater was collected by filtering through combusted $0.7 \mu \mathrm{m}$ Glass Fiber Filters (Whatman). Filters were desiccated at $50^{\circ} \mathrm{C}$ after removing carbonate with $\mathrm{HCl}$ vapor. $\mathrm{POC}$ and particulate nitrogen on filters were analyzed on Thermo NC analyzer.

Electron microscopy. One-ml subsamples were taken from incubations and centrifuged at $4,000 \mathrm{~g}$ for $20 \mathrm{~min}$. The pellets were washed and resuspended in $0.1 \mathrm{ml}$ of distilled water. One drop of the sample was fixed onto 300-mesh carboncoated copper grids for $60 \mathrm{~s}$ before being air-dried for TEM analysis.

Prepared grids were viewed on a JEOL JEM-1400 TEM at an accelerating voltage of $120 \mathrm{kV}$. Selected area diffraction mode was applied on interesting parts of the samples.

Thin sections were prepared by centrifuging $45-\mathrm{ml}$ subsamples from cyanobacterial incubations at $5,525 \mathrm{~g}$ for $40 \mathrm{~min}$. The pellets were fixed with $3 \%$ glutaraldehyde $/ 0.05 \mathrm{M}$ phosphate buffer $(\mathrm{pH}=7)$, and kept at $4{ }^{\circ} \mathrm{C}$ overnight. The samples were then dehydrated with ethyl alcohol. The samples were then stained with lead citrate and uranyl acetate. After being embedded in Epon resin, the samples were cut into ultrathin 80 -nm sections with a Reichert-Jung Ultracut E Ultramicrotome. Thin sections were placed on Formvar-coated slot copper grids, and TEM images were taken using an FEI BioTwinG2 Transmission Electron Microscope. The same grid was further analyzed on a JEOL 7600 analytical SEM with an Oxford energy dispersive X-ray spectrometer in STEM mode.

Filtered particles from the Bermuda Rise sampling site were dried at $55^{\circ} \mathrm{C}$ overnight. The dried filters were coated with gold on an aluminium sample holder, and SEM images were taken using a JEOL 7600 analytical SEM with an Oxford energy dispersive X-ray spectrometer .

Amino acid analysis. Dissolved hydrolysable amino acids and particulate amino acids were analyzed during the degradation experiment. Individual amino acids were measured after hydrolysis in both particles (pellets that contained cell detritus and other particles) and surrounding seawater (supernatant) from the Synechococcus incubations ${ }^{33}$. Samples were hydrolyzed at $110^{\circ} \mathrm{C}$ in $6 \mathrm{~N} \mathrm{HCl}$ (Trace metal basis, Sigma-Aldrich) and $0.11 \mu \mathrm{mol} \mathrm{l}^{-1}$ ascorbic acid (Sigma-Aldrich) for $20 \mathrm{~h}$. The acid was removed by nitrogen sparging. D- and L-amino acids were chirally derivatized with o-phthaldialdehyde (Sigma-Aldrich) and N-isobutyryl-L-cysteine (Fluka). D- and L- amino acids were separated by high performance liquid chromatography with fluorescence detection (Excitation/Emission $=330 / 445 \mathrm{~nm}$ ). Only L-amino acids were included in calculations of dissolved and particulate amino acid composition. Pierce $\mathrm{H}$ amino acid standard was mixed with individual D-amino acid standards to result in a mixed standard for both D- and L-amino acids; beta-alanine and gamma-aminobutyric acid were also added.

\section{References}

1. Agawin, N. S. R., Duarte, C. M. \& Agusti, S. Nutrient and temperature control of the contribution of picoplankton to phytoplankton biomass and production. Limnol. Oceanogr. 45, 591-600 (2000).

2. Steinberg, D. K. et al. Overview of the US JGOFS Bermuda Atlantic Time-series Study (BATS): a decade-scale look at ocean biology and biogeochemistry. Deep-Sea Res. II 48, 1405-1447 (2001).

3. Buesseler, K. O. The decoupling of production and particulate export in the surface as a tracer of upper ocean. Glob. Biogeochem. Cycles 12, 297-310 (1998).

4. Armstrong, R. A., Lee, C., Hedges, J. I., Honjo, S. \& Wakeham, S. G. A new, mechanistic model for organic carbon fluxes in the ocean based on the quantitative association of POC with ballast minerals. Deep-Sea Res. II 49, 219-236 (2002).

5. Armstrong, R. A., Peterson, M. L., Lee, C. \& Wakeham, S. G. Settling velocity spectra and the ballast ratio hypothesis. Deep-Sea Res. II 56, 1470-1478 (2009).

6. Richardson, T. L. \& Jackson, G. A. Small phytoplankton and carbon export from the surface ocean. Science 315, 838-840 (2007).

7. Dong, H.-P., Wang, D.-Z., Dai, M. \& Hong, H.-S. Characterization of particulate organic matter in the water column of the South China Sea using a shotgun proteomic approach. Limnol. Oceanogr. 55, 1565-1578 (2010).

8. Lomas, M. W. \& Moran, S. B. Evidence for aggregation and export of cyanobacteria and nano-eukaryotes from the Sargasso Sea euphotic zone. Biogeosciences 8, 203-216 (2011).

9. Verdugo, P. Marine microgels. Annu. Rev. Mar. Sci. 4, 375-400 (2012).

10. Santschi, P. H. et al. Fibrillar polysaccharides in marine macromolecular organic matter as imaged by atomic force microscopy and transmission electron microscopy. Limnol. Oceanogr. 43, 896-908 (1998).

11. Strycek, T. et al. Extracellular fibril production by freshwater algae and cyanobacteria. Microb. Ecol. 23, 53-74 (1992).

12. Pereira, S. et al. Complexity of cyanobacterial exopolysaccharides: composition, structures, inducing factors and putative genes involved in their biosynthesis and assembly. FEMS Microbiol. Rev. 33, 917-941 (2009).

13. Decho, A. W. Microbial exopolymer secretions in ocean environments-their role(s) in food webs and marine processes. Oceanogr. Mar. Biol. 28, 73-153 (1990).

14. Ransom, B., Bennett, R. H., Baerwald, R. \& Shea, K. TEM study of in situ organic matter on continental margins: occurrence and the 'monolayer' hypothesis. Mar. Geol. 138, 1-9 (1997).

15. Konhauser, K. O. \& Urrutia, M. M. Bacterial clay authigenesis: a common biogeochemical process. Chem. Geol. 161, 399-413 (1999).

16. Ingalls, A. E., Lee, C., Wakeham, S. G. \& Hedges, J. I. The role of biominerals in the sinking flux and preservation of amino acids in the Southern Ocean along 170W. Deep-Sea Res. II 50, 713-738 (2003).

17. Bidle, K. D. \& Azam, F. Accelerated dissolution of diatom silica by marine bacterial assemblages. Nature 397, 508-512 (1999).

18. Brzezinski, M. A. The Si:C:N ratio of marine diatoms: interspecific variability the effect of some environmental variables. J. Phycol. 21, 347-357 (1985).

19. Tesson, B., Gaillard, C. \& Martin-Jézéquel, V. Brucite formation mediated by the diatom Phaeodactylum tricornutum. Mar. Chem. 109, 60-76 (2008).

20. DeMaster, D. J. in Treatise on Geochemistry Vol. 7 (ed. Mackenzie, F.T.) 87-98 (Elsevier, the Netherlands, 2003).

21. Benning, L. G., Phoenix, V. R., Yee, N. \& Tobin, M. J. Molecular characterization of cyanobacterial silicification using synchrotron infrared micro-spectroscopy. Geochim. Cosmochim. Acta 68, 729-741 (2004).

22. Baines, S. B. et al. Significant silicon accumulation by marine picocyanobacteria. Nat. Geosci. 5, 886-891 (2012).

23. Close, H. G. et al. Export of submicron particulate organic matter to mesopelagic depth in an oligotrophic gyre. Proc. Natl Acad. Sci. USA 110, 12565-12570 (2013).

24. Casey, J. R., Aucan, J. P., Goldberg, S. R. \& Lomas, M. W. Changes in partitioning of carbon amongst photosynthetic pico- and nano-plankton groups in the Sargasso Sea in response to changes in the North Atlantic Oscillation. Deep-Sea Res. II 93, 58-70 (2013).

25. Awramik, S. M. The oldest records of photosynthesis. Photosynth. Res. 33, 75-89 (1992).

26. Walter, M. R., Bauld, J. \& Brock, T. D. Siliceous algal and bacterial stromatolites in hot spring and geyser effluents of Yellowstone National Park. Science 178, 402-405 (1972).

27. Michalopoulos, P. \& Aller, R. C. Early diagenesis of biogenic silica in the Amazon delta: alteration, authigenic clay formation, and storage. Geochim. Cosmochim. Acta 68, 1061-1085 (2004).

28. Yee, N., Phoenix, V. R., Konhauser, K. O., Benning, L. G. \& Ferris, F. G. The effect of cyanobacteria on silica precipitation at neutral $\mathrm{pH}$ : implications for bacterial silicification in geothermal hot springs. Chem. Geol. 199, 83-90 (2003).

29. Krause, J. W. et al. The effects of biogenic silica detritus, zooplankton grazing, and diatom size structure on silicon cycling in the euphotic zone of the eastern equatorial Pacific. Limnol. Oceanogr. 55, 2608-2622 (2010).

30. Collier, J. L. \& Grossman, A. R. Chlorosis induced by nutrient deprivation in Synechococcus sp. strain PCC 7942: not all bleaching is the same. J. Bacteriol. 174, 4718-4726 (1992).

31. DeMaster, D. J. The supply and accumulation of silica in the marine environment. Geochim. Cosmochim. Acta 45, 1715-1732 (1981).

32. Mullin, J. B. \& Riley, J. P. The spectrophotometric determination of silicatesilicon in natural waters with special reference to seawater. Anal. Chim. Acta 46, 491-501 (1965). 
33. Fitznar, H. P., Lobbes, J. M. \& Kattner, G. Determination of enantiomeric amino acids with high-performance liquid chromatography and pre-column derivatisation with o-phthaldialdehyde and $\mathrm{N}$-isobutyrylcysteine in seawater and fossil samples (mollusks). J. Chromatogr. A 832, 123-132 (1999).

\section{Acknowledgements}

We thank the captain and crew of R/V Endeavour for assistance with field sampling, and D. Hirschberg and S. Ray for assistance with silicate and POC analysis. We thank S.V. Horn from CMIC (Stony Brook University) for TEM and scanning transmission electron microscope sample preparation, and J. Collier, B. Aller and S.B. Baines for their comments. This work was supported by NSF OCE1061128. Electron microscopy work was carried out at the Center for Functional Nanomaterials, the Brookhaven National Laboratory, which is supported by the US Department of Energy, the Office of Basic Energy Sciences, under Contract No. DE-AC02-98CH10886. This is contribution 1362 of the School of Marine and Atmospheric Sciences, Stony Brook University.

\section{Author contributions}

K.K. conducted the TEM and SEM analysis at the Brookhaven National Laboratory. T.T conducted all the other work including TEM and SEM sample preparation. The manuscript was prepared by T.T. and C.L.

\section{Additional information}

Supplementary Information accompanies this paper at http://www.nature.com/ naturecommunications

Competing financial interests: The authors declare no competing financial interests

Reprints and permission information is available online at http://npg.nature.com/ reprintsandpermissions/

How to cite this article: Tang, T. et al. Silicate deposition during decomposition of cyanobacteria may promote export of picophytoplankton to the deep ocean. Nat. Commun. 5:4143 doi: 10.1038/ncomms5143 (2014). 